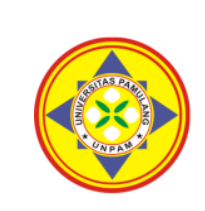
PERYUSS

\title{
PENGARUH GAYA KEPEMIMPINAN DAN KOMPENSASI TERHADAP KINERJA KARYAWAN PADA PT MATA MILENIAL INDONESIA
}

\author{
${ }^{*}$ Ela Hulasoh, ${ }^{2}$ Sri Wulandari \\ Universitas Pamulang, Tangerang Selatan, Banten, Indonesia \\ *dosen01910@unpam.ac.id
}

\begin{abstract}
Abstrak
Penelitian ini bertujuan untuk mengentahui pengaruh gaya kepemimpinan dan kompensasi terhadap kinerja karyawan PT Mata Milenial Indonesia. Metode yang digunakan adalah kuantitatif asosiatif dengan populasi sebanyak 60 responden dengan teknik analisis datanya menggunakan uji validitas, uji reliabilitas dan uji asumsi klasik, analisis regresi linier berganda, analisis regresi linier sederhana, uji t, uji F, uji R2 dan uji koefisien korelasi. Hasil dari penelitian ini didapatkan gaya kepemimpinan terbukti berpengaruh positif signifikan terhadap kinerja karyawan dengan nilai koefisien regresi sebesar 0.579 , nilai thitung sebesar 6.723 lebih besar dari 2.002 dan nilai signifikansi sebesar 0,000 lebih kecil dari 0,05Gaya kepemimpinan dan kompensasi secara simultan berpengaruh positif dan signifikan terhadap kinerja karyawan, hasil perhitungan uji $\mathrm{F}$, diketahui bahwa nilai Fhitung > Ftabel atau 70.334>2.76 dan nilai signifikansi sebesar 0.000 lebih kecil dari 0,05.
\end{abstract}

Kata Kunci: Gaya Kepemimpinan, Kompensasi dan Kinerja

\section{Abstract}

This research aims to explore the influence of leadership style and compensation on the performance of EMPLOYEES of PT Mata Mileni Indonesia. The method used is quantitative associative with a population of 60 respondents with its data analysis techniques using validity tests, reliability tests and classical assumption tests, multiple linear regression analysis, simple linear regression analysis, $t$ test, $F$ test, $R 2$ test and correlation coefficient test. The results of this study obtained leadership style proved to have a significant positive effect on employee performance with a regression coefficient value of 0.579 , a thitung value of 6,723 greater than 2,002 and a significance value of 0.000 smaller than 0.05 Leadership and compensation simultaneously positive and significant effect on employee performance, the results of $F$ test calculations, it is known that the value of Fhitung $>$ Ftabel or 70,334>2.76 and significance value of 0.000 is smaller than 0.05 .

Keywords: Leadership Style, Compensation and Performance

\section{PENDAHULUAN}

Pemimpin merupakan seseorang yang mempunyai keputusan tertinggi untuk setiap aturan dan kebijakan yang akan dijalankan serta merupakan tokoh utama dalam kemajuan dan keunggulan suatu perusahaan. Setiap perusahaan tentu mengharapkan pemimpin yang dapat membawa institusi mencapai kinerja yang baik secara berkelanjutan. Namun kurangnya komunikasi antara pimpinan dengan para karyawan membuat beberapa permasalahan menjadi lamban untuk diselesaikan. Kemampuan dalam menjalin hubungan yang baik dengan semua unsur di perusahaanpun tidak dapat dilakukan dengan maksimal.

Selain pentingnya peranan pemimpin untuk meningkatkan kinerja karyawan, kompensasi juga merupakan hal penting. Salah satu tujuan didirikannya perusahaan yaitu untuk memberikan kesejahteraan kepada mereka yang terlibat dalam aktivitas perusahaan. Untuk menunjang kesejahteraan para karyawan serta dalam memenuhi kewajiban perusahaan terhadap hak-hak karyawan maka pengaturan pemberian kompensasi harus diatur dengan sebaik-baiknya. Kompensasi dapat 
menjadi dorongan agar karyawan terus meningkatkan kemampuannya. Pada akhirnya pengaturan kompensasi yang baik akan memberikan keuntungan bagi karyawan maupun manajemen dalam hal ini berpengaruh terhadap kinerja karyawan.

kinerja yang dihasilkan oleh karyawan juga menentukan kualitas perusahaan tersebut. Setiap karyawan pasti sudah mempunyai tugas dalam posisi masing-masing dan harus dikerjakan dengan baik. Hal ini akan berpengaruh pada penilaian kinerja. Para karyawan harus mempunyai sikap tanggung jawab dalam menyelesaikan pekerjaannya, juga tentunya harus memenuhi standar kualitas dan kuantitas yang sudah ditetapkan.

\section{TINJAUAN PUSTAKA}

1. Gaya Kepemimpinan

Menurut Sutrisno (2016: 222) gaya kepemimpin adalah perilaku atau cara yang dipilih dan dipergunakan pemimpin dalam mempengaruhi pikiran, perasaan, sikap dan perilaku para anggota organisasi bawahannya. Dari pendapat beberapa ahli di atas maka penulis menarik kesimpulan bahwa gaya kepemimpinan adalah gaya seorang pemimpin yang meliputi sikap, cara berpikir yang digunakan untuk mempengaruhi bawahannya agar mau bekerjasama untuk mencapai tujuan perusahaan.

2. Kompensasi

Menurut Yani dalam buku Widodo (2018: 153) kompensasi adalah bentuk pembayaran dalam bentuk manfaat dan insentif untuk memotivasi karyawan agar produktivitas kerja semakin meningkat.

3. Kinerja

Menurut Kasmir (2019: 182) "kinerja merupakan hasil kerja dan perilaku kerja yang telah dicapai dalam melaksanakan tugas-tugas dan tanggung jawab yang diberikan dalam suatu periode tertentu".

\section{METODE}

Dalam penelitian ini yang menjadi populasi adalah seluruh karyawan yang bekerja pada PT. Mata Milenial Indonesia dengan jumlah karyawan sebanyak 60 orang. Teknik sampling yang digunakan dalam penelitian ini adalah sampling jenuh yaitu seluruh karyawan PT. Mata Milenial Indonesia berjumlah 60 orang.. Menurut Sugiyono (2019: 85) “sampling jenuh adalah teknik penentuan sampel bila semua anggota populasi digunakan sebagai sampel. Istilah lain sampel jenuh adalah sensus, dimana semua populasi dijadikan sampel".

Jenis penelitian yang dipakai adalah asosiatif, dimana tujuannya adalah untuk mengetahui atau mencari keterhubungan antara variabel independen terhadap variabel dependennya. Dalam menganalisis data digunakan uji validitas, uji reliabilitas, uji asumsi klasik, analisis regresi linier sederhana, analisis regresi linier berganda, analisis koefisien korelasi, analisis koefisien determinasi (R2) dan pengujian hipotesis (Uji t), uji F.

\section{HASIL DAN PEMBAHASAN}

\section{Analisis Deskriptif}

Pada pengujian ini digunakan untuk mengetahui skor minimum dan maksimum skor tertinggi, ratting score dan standar deviasi dari masing-masing variabel. Adapun hasilnya sebagai berikut:

Variabel gaya kepemimpinan diperoleh ratting score sebesar 2,858 berada di rentang skala 2,60 - 3,39 dengan kriteria kurang baik atau raguragu.

1. variabel kompensasi diperoleh ratting score sebesar 2,656. berada di rentang skala 2,60 - 3,39 dengan kriteria kurang baik atau ragu-ragu.

2. Kinerja karyawan dipersepsikan tidak baik dengan rata-rata skor sebesar 2,11 yang berarti tidak baik atau tidak setuju. 
2. Analisis Verifikatif

Pada analisis ini dimaksudkan untuk mengetahui pengaruh variabel independen terhadap variabel dependen. Adapun hasil pengujian sebagai berikut:

a. Analisis Regresi Linier Sederhana

Tabel 1. Hasil Pengujian Regresi Linier Sederhana Variabel X1 (Gaya Kepemimpinan)

\begin{tabular}{|c|c|c|c|c|c|c|}
\hline \multicolumn{4}{|c|}{ UnstandardizedCoefficients } & \multirow{2}{*}{$\begin{array}{l}\text { Standardized Coefficients } \\
\text { Beta }\end{array}$} & \multirow[b]{2}{*}{$\mathrm{T}$} & \multirow[b]{2}{*}{ Sig. } \\
\hline Mode & & $\mathrm{B}$ & Std. Error & & & \\
\hline \multirow[t]{2}{*}{1} & (Constant) & 3.909 & 1.518 & & 2.575 & .013 \\
\hline & GAYAKEPEMIMPINAN & .601 & .050 & .843 & 11.948 & .000 \\
\hline
\end{tabular}

Coefficients $^{\mathrm{a}}$

Table 2. Hasil Pengujian Regresi Linier Sederhana Variable X2 (Kompensasi)

\begin{tabular}{|c|c|c|c|c|c|c|}
\hline \multicolumn{2}{|c|}{ Coefficients ${ }^{\mathrm{a}}$} & \multicolumn{2}{|c|}{$\begin{array}{l}\text { Unstandardized } \\
\text { Coefficients }\end{array}$} & \multirow{2}{*}{$\begin{array}{l}\text { Standardized } \\
\text { Coefficients } \\
\text { Beta }\end{array}$} & \multirow[b]{2}{*}{$\mathrm{T}$} & \multirow[b]{2}{*}{ Sig. } \\
\hline & & B & Std. Error & & & \\
\hline \multirow[t]{2}{*}{1} & (Constant) & 9.807 & 1.665 & & 5.890 & .000 \\
\hline & KOMPENSASI & .425 & .058 & .695 & 7.361 & .000 \\
\hline
\end{tabular}

Berdasarkan hasil pengujian pada table di atas, diperoleh persamaan regresi $Y=3,909+0,601 X$. Dari persamaan tersebut dijelaskan bahwa nilai konstanta sebesar 3.909 artinya apabila gaya kepemimpinan itu sama dengan nol maka kinerja karyawan akan bernilai sama besar 3.909 , setelah itu koefisien gaya kepemimpinan sebesar 0,601 artinya bahwa setiap satu satuan gaya kepemimpinan maka kinerja karyawan akan mengalami kenaikan sebesar 0,601.

Berdasarkan penjelasan di atas pada table 3 bahwa nilai konstanta

Tabel 3. Hasil Pengujian Koefisien Korelasi Gaya Kepemimpinan dan Kompensasi Terhadap Kinerja Karyawan.

GAYA KEPEMIMPINAN KOMPENSASI

\begin{tabular}{|c|c|c|c|c|}
\hline & & GAYA KEPEMIMPINAN & KOMPENSASI & $\begin{array}{l}\text { KINERJA } \\
\text { KARYAWAN }\end{array}$ \\
\hline \multirow[t]{3}{*}{ GAYA KEPEMIMPINAN } & Pearson Correlation & 1 & $.808^{* *}$ & $.843^{* *}$ \\
\hline & Sig. (2- tailed) & & .000 & .000 \\
\hline & $\mathrm{N}$ & 60 & 60 & 60 \\
\hline \multirow[t]{3}{*}{ KOMPENSASI } & Pearson Correlation & $.808^{* *}$ & 1 & $.695^{* *}$ \\
\hline & Sig. (2- tailed) & .000 & & .000 \\
\hline & $\mathrm{N}$ & 60 & 60 & 60 \\
\hline \multirow{3}{*}{$\begin{array}{l}\text { KINERJAKARYA } \\
\text { WAN }\end{array}$} & Pearson Correlation & $.843^{* *}$ & $.695^{* *}$ & 1 \\
\hline & Sig. (2- tailed) & .000 & .000 & \\
\hline & $\mathrm{N}$ & 60 & 60 & 60 \\
\hline
\end{tabular}
diperoleh nilai korelasi variabel gaya kepemimpinan dengan kinerja karyawan sebesar 0.843 masuk pada
Berdasarkan hasil pengujian sebesar 9.807 artinya apabila kompensasi itu sama dengan nol maka kinerja karyawan akan bernilai sama besar 9.807, setelah itu koefisien kompensasi sebesar 0,425 artinya bahwa setiap satu satuan kompensasi maka kinerja karyawan akan mengalami kenaikan sebesar 0,425.

b. Analisis Koefisien Korelasi

Analisis koefisien korelasi dimaksudkan untuk mengetahui tingkat kekuatan hubungan dari variabel independen terhadap variabel dependen. Adapun hasil pengujian sebagai berikut: kategori "sangat kuat". Sedangkan nilai korelasi antara kompensasi dengan kinerja karyawan sebesar 0.695 masuk pada kategori kuat. 
Dengan kata lain, terdapat hubungan yang kuat antara variabel gaya kepemimpinan dan kompensasi dengan kinerja karyawan.

c. Analisis Koefisien Determinasi
Analisis koefisien determinasi dimaksudkan untuk mengetahui besarnya persentase pengaruh dari variabel independen terhadap variabel dependen. Adapun hasil pengujian sebagai berikut:

Tabel 4. Hasil Pengujian Koefisien Determinasi Gaya Kepemimpinan dan Kompensasi Terhadap Kinerja Karyawan.

\begin{tabular}{ll|l|l|l} 
Model & R & R Square & Adjusted R Square & $\begin{array}{l}\text { Std. Error of the } \\
\text { Estimate }\end{array}$ \\
\hline 1 & $.844^{\mathrm{a}}$ & .712 & .702 & 3.777 \\
\hline
\end{tabular}

Berdasarkan hasil pengujian diperoleh nilai determinasi sebesar sebesar 0,702. Artinya gaya kepemimpinan dan kompensasi memiliki kemampuan menjelaskan variabel kinerja karyawan sebesar $70,2 \%$ sedangkan sisanya sebesar $29,8 \%$ dijelaskan oleh variabel lain di luar penelitian ini.

Tabel 5. Hasil Uji Hipotesis Gaya Kepemimpinan dan Kompensasi Terhadap Kinerja Karyawan.

\begin{tabular}{|c|c|c|c|c|c|c|}
\hline & & $\begin{array}{l}\text { Unsta } \\
\text { Coeffi }\end{array}$ & & $\begin{array}{l}\text { Standardized } \\
\text { Coefficients }\end{array}$ & $\mathrm{t}$ & Sig. \\
\hline \multicolumn{2}{|l|}{ Model } & B & Std. Error & Beta & & \\
\hline \multirow[t]{2}{*}{1} & (Constant) & 9.807 & 1.665 & & 5.890 & .000 \\
\hline & KOMPENSASI & .425 & .058 & .695 & 7.361 & .000 \\
\hline
\end{tabular}

a. Bahwa nilai konstanta sebesar 9.807 memiliki arti, meskipun tidak ada pengaruh dari variabel kompensasi, karyawan PT. Mata Milenial Indonesia tetap memiliki kinerja karyawan sebesar 9.807.

b. Variabel kompensasi memiliki nilai thitung lebih besar dari ttabel d. Uji Hipotesis

Pengujian hipotesis dengan uji $\mathrm{t}$ digunakan untuk mengetahui hipotesis mana yang diterima.

Rumusan hipotesis: Terdapat pengaruh yang signifikan antara pelayanan terhadap kepuasan pasien.
(7.361>2.002). Artinya kompensasi tidak berpengaruh positif terhadap kinerja karyawan.

c. Variabel kompensasi memiliki nilai signifikan lebih kecil dari 0,05 $(0.000<0,05)$. Artinya kompensasi tidak berpengaruh signifikan terhadap kinerja kayawan.

e. Uji F

Tabel 6. Hasil Uji Hipotesis Gaya Kepemimpinan dan Kompensasi Terhadap Kinerja Karyawan.

\begin{tabular}{|c|c|c|c|c|c|c|c|}
\hline Model & & Sum & of Squares & $\mathrm{df}$ & Mean Square & $\mathrm{F}$ & Sig \\
\hline \multirow[t]{3}{*}{1} & Regression & 2006.389 & & 2 & 1003.195 & 70.334 & $.000^{\mathrm{b}}$ \\
\hline & Residual & 813.011 & & 57 & 14.263 & & \\
\hline & Total & 2819.400 & & 59 & & & \\
\hline
\end{tabular}

Berdasarkan tabel di atas, diketahui bahwa nilai $\mathrm{F}$ hitung sebesar 70.334 lebih besar dari $\mathrm{F}$ tabel sebesar 2.76 dan nilai signifikansi sebesar 0.000 lebih kecil dari 0,05. Maka dapat disimpulkan bahwa gaya kepemimpinan dan kompensasi secara simultan berpengaruh positif dan signifikan terhadap kinerja karyawan.
PEMBAHASAN HASIL PENELITIAN

1. Kondisi Jawaban Responden Variabel Gaya Kepemimpinan

Berdasarkan jawaban responden, variabel gaya kepemimpinan diperoleh ratting score sebesar 2,858 berada di rentang skala 2,60 - 3,39 dengan kriteria kurang baik atau ragu-ragu.

2. Kondisi Jawaban Responden Variabel Kompensasi 
Berdasarkan jawaban responden, variabel kompensasi diperoleh ratting score sebesar 2,656. berada di rentang skala 2,60 - 3,39 dengan kriteria kurang baik atau ragu-ragu.

3. Pengaruh Gaya Kepemimpinan dan Kompensasi Terhadap Kinerja Karyawan

diketahui kinerja karyawan di PT. Mata Milenial Indonesia dipersepsikan tidak baik dengan rata-rata jawaban sebesar 2,11 . Adapun penilaian kinerja karyawan yang dipersepsikan paling rendah adalah indikator inisiatif yakni kuesioner nomor 7 yang berbunyi "Saya selalu memberikan ide-ide baru untuk kemajuan perusahaan" dengan rata-rata jawaban sebesar 2,7.

\section{PENUTUP}

\section{Kesimpulan}

1. Variabel Gaya kepemimpinan terbukti berpengaruh positif signifikan terhadap kinerja karyawan. Hal ini dapat ditunjukkan oleh nilai koefisien regresi sebesar 0.579 , nilai thitung sebesar 6.723 lebih besar dari 2.002 dan nilai signifikansi sebesar 0,000 lebih kecil dari 0,05 .

2. Variable Kompensasi terbukti tidak berpengaruh signifikan terhadap kinerja karyawan, dalam hal ini dapat ditunjukan oleh nilai koefisien regresi sebesar 0.024 , nilai thitung sebesar 0.325 lebih kecil dari ttabel yaitu 2,002 $(0,325<$ 2.002) dan nilai signifikansi sebesar 0,746 lebih besar dari $0,05(0,746>0,05)$.

3. Variabel Berdasarkan hasil perhitungan uji $\mathrm{F}$, diketahui bahwa nilai Fhitung $>$ Ftabel atau $70.334>2.76$ dan nilai signifikansi sebesar 0.000 lebih kecil dari 0,05. Maka dapat disimpulkan bahwa gaya kepemimpinan dan kompensasi secara simultan berpengaruh positif dan signifikan terhadap kinerja karyawan

\section{Saran}

1. Berdasarkan hasil penyebaran kuesioner, variabel gaya kepemimpinan mendapat penilaian kurang baik. Dengan nilai terendah yaitu "Atasan selalu melibatkan karyawan dalam pengambilan keputusan" dengan ratarata jawaban sebesar 2,56. Maka dari itu disarankan perlu adanya koordinasi yang harus ditingkatkan, agar setiap keputusan yang dambil dapat dijalankan dengan baik oleh semua bagian di perusahaan.

2. Berdasarkan hasil penyebaran kuesioner, variabel kompensasi mendapat penilaian kurang baik. Dengan nilai terendah yaitu "Bonus yang saya terima sudah sesuai prestasi kerja saya" dengan rata-rata jawaban sebesar 1,98. Dari hasil tesebut disarankan agar perusahaan membuat peraturan untuk menetapkan besaran bonus yang akan diterima karyawan apabila mencapai prestasi kerja yang telah ditentukan.

3. Berdasarkan hasil penyebaran kuesioner, variabel kinerja karyawan mendapat penilaian kurang baik. Dengan nilai terendah yaitu "Saya selalu memberikan ide-ide baru untuk kemajuan perusahaan" dengan rata-rata jawaban sebesar 2,76. Dari hasil disarankan tersebut agar karyawan dapat berkontribusi dalam memberikan ide-ide untuk perusahaan untuk kemajuan perusahaan kedepannya.

\section{DAFTAR PUSTAKA}

Agusentoso, Randhy. (2018). Pengaruh Kompensasi Terhadap Kinerja Karyawan pada PT. JCO Donuts \& Coffe BSD Square Tangerang Selatan. Jurnal Ekonomi Efektif, Vol.1, No.3, Juni 2019 ISSN: 2622-8882.

Chair, Ma'ruf Ummul. (2020). Pengaruh Motivasi Kerja Terhadap Kinerja Karyawan pada PT. Nirha Jaya Teknik Makassar. Jurnal Brand, Volume 2 No. 1, Juni 2020 ISSN : 27154920.

Feriyanto, Andri \& Endang. (2015). Pengantar Manajemen (3 in 1). Yogyakarta: Penerbit Media Tera.

Ghozali, Imam. (2016). Aplikasi Analisis Multivariate Dengan Program IBM SPSS. Semarang: Badan PenerbitUndip. 
Ghozali, Imam. (2018). Aplikasi Analisis Multivariate Dengan Program IBM SPSS 25 Edisi 9. Semarang: Badan Penerbit-Undip.

Hamdiyah. (2016). Peningkatan Kinerja Karyawan Melalui Kompensasi, Lingkungan Kerja dan Gaya Kepemimpinan di Ada Swalayan Bayumanik Semarang. Journal of Management Vol.02 No.02, Maret 2016.

Hasan, Iqbal \& Misbahudin. (2014). Analisis Data Penelitian Dengan Statistik. Bumi Aksara: Jakarta

Hasibuan, M.S.P. (2017). Manajemen Sumber Daya Manusia. Bumi Aksara: Jakarta.

Hermawati, R., et al. (2020). The Effect of Trilogy Leadership Style and Organization Culture on School Performance: Evidence form Indonesian Senior High School. PalArch's Journal of Archaeology of Egypt/Egyptology, 17(6), 85128537.Fdisiplin

Kartono \& Kartini. (2014). Pemimpin dan Kepemimpinan. Jakarta: PT Raja Grafindo Persada.

Kasenda, Ririvega. (2016). Kompensasi dan Motivasi Pengaruhnya Terhadap Kinerja Karyawan pada PT. Bangun Wenang Beverages Company Manago. Jurnal EMBA Universitas Samratulangi. Vol.1 No.3, Hal.853859.

Kasmir. (2019). Manajemen Sumber Daya Manusia (Teori dan Praktik). Depok: PT Raja Grafindo Persada.

Kurniawan, Mohd D.P. (2018). Pengaruh Gaya Kepemimpinan Terhadap Kinerja Karyawan Percetakan Dimas Kota Palembang. Jurnal Ilmiah Manajemen Bisnis Dan Terapan, Vol.15, No. 1,

Mangkunegara, A.P. (2013). Manajemen Sumber Daya Manusia Perusahaan. Bandung: Remaja Rosdakarya.

Mangkunegara, A.P. (2014). Manajemen Sumber Daya Manusia Perusahaan. Bandung: Remaja Rosdakarya.
Manik, Sudarmin. (2016). Pengaruh Kepuasan Kerja Terhadap Disiplin KerjaPegawai Kantor Camat Pendalian IV Koto Kabupaten Rokan Hulu. International Journal of Social Science and Business. Vol. 1(4).

Nurjaya, N., et al. (2021). Pengaruh Kompetensi Sumber Daya Manusia Dan Kemampuan Pemanfaatan Teknologi Terhadap Kinerja Aparatur Desa Pada Kantor Kepala Desa Di

Kabupaten Gunungkidul, Yogyakarta. JENIUS (Jurnal Ilmiah Manajemen Sumber Daya Manusia), 4(3), 332-346.

Panggabean. (2014). Manajemen Sumber Daya Manusia. Bogor: Ghalia Indonesia.

Pawar, A., et al. (2020). Organizational Servant Leadership. International Journal of Educational Administration, Management, and Leadership, 63-76.

Pratama, S.A, dkk. (2015). Pengaruh Kompensasi Terhadap Kinerja Karyawan Pada PT. Asuransi Jiwasraya Persero Regional Office Malang. Jurnal Administrasi Bisnis Universitas Brawiyaja Malang. Vol.5 No.1, Hal.1-8.

Pratama, Stefanus Andi. (2016). Pengaruh Kompensasi Terhadap Kinerja Karyawan (Studi pada karyawan PT. Asuransi Jiwasraya persero regional office Malang). Jurnal Administrasi Bisnis Universitas Brawijaya Malang Vol. 25 No. 1 Halaman 1 - 8

Rivai, V \& Mulyadi, D. (2012). Kepemimpinan dan Perilaku Organisasi Edisi Ketiga. Jakarta : PT Raja Grafindo Persada.

Setiawan, K.A, Ni Wayan Mujiati. (2016). Pengaruh Gaya Kepemimpinan dan Kompensasi pada PT. Astra Honda Nusa Dua Kabupaten Badung. EJurnal Manajemen Unud, Vol. 5, No. 12, 2016: 7956-7983 ISSN: 2302-8912

Sugiyono. (2016). Metode Penelitian Kuantitatif Kualitatif dan R\&D. Bandung : Alfabeta.

Sunyoto, D \& Susanti, F. E. (2019). Kepemimpinan Manajerial: Kajian 
Peranan Penting Kepemimpinan dalam Kerangka Manajemen. Yogyakarta: Center for Academic Publishing Service.

Sutrisno, E. (2016). Manajemen Sumber Daya Manusia. Jakarta: Kencana Prenada Media Group.

Suwondo, D.I. (2015). Hubungan Lingkungan Kerja, Disiplin Kerja dan Kinerja Karyawan. Jurnal Manajemen dan Kewirausahaan Universitas Kristen Petra. Vol.17 No.2, Hal. 135144.
Trang, D.S. (2013). Gaya Kepemimpinan dan Budaya Organisasi Pengaruhnya Terhadap Kinerja Karyawan. Jurnal EMBA Vol.1 No.3 September 2013, Hal. 208-216.

Widodo, S. E. (2018). Manajemen Pengembangan Sumber Daya Manusia. Yogyakarta: Pustaka Belajar.

Wilandari, D. F., et al (2021). Pengaruh Penilaian Kerja Terhadap Kinerja Karyawan Pada PT. Jaya Mandiri Rekabuana di Cilandak. Jurnal Ekonomi Efektif, 3(2). 